University of Nebraska - Lincoln

DigitalCommons@University of Nebraska - Lincoln

\title{
$5-1988$
}

\section{Subtilitas in the tonal language of Fumeux fume}

Peter M. Lefferts

University of Nebraska-Lincoln, plefferts1@unl.edu

Follow this and additional works at: https://digitalcommons.unl.edu/musicfacpub

Part of the Music Commons

Lefferts, Peter M., "Subtilitas in the tonal language of Fumeux fume" (1988). Faculty Publications: School of Music. 46.

https://digitalcommons.unl.edu/musicfacpub/46

This Article is brought to you for free and open access by the Music, School of at DigitalCommons@University of Nebraska - Lincoln. It has been accepted for inclusion in Faculty Publications: School of Music by an authorized administrator of DigitalCommons@University of Nebraska - Lincoln. 


\section{Subtilitas in the tonal language of Fumeux fume}

\section{Peter M. Lefferts}

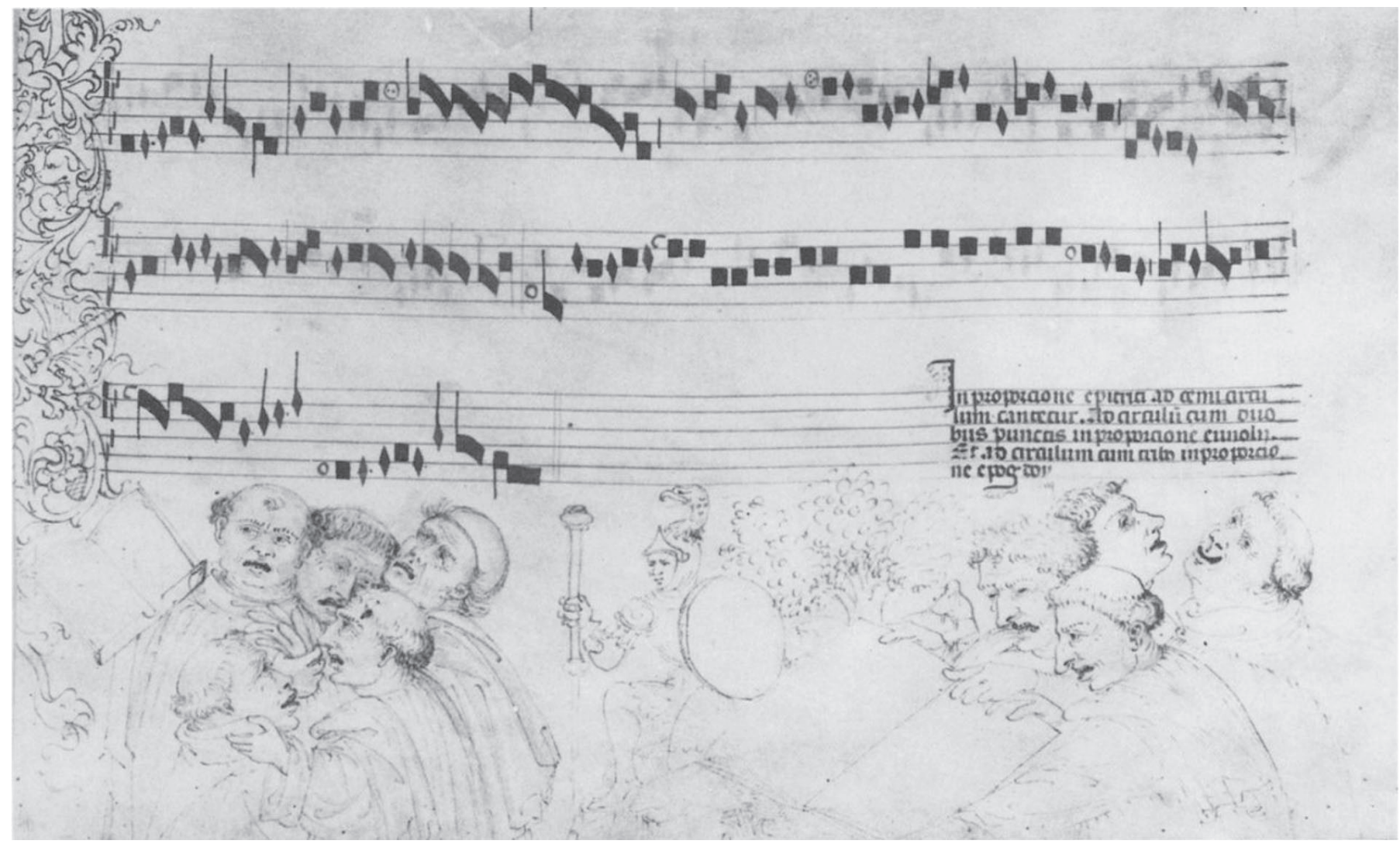

Figure 1. Groups of singers depicted in the manuscript containing Fumeux fume (Chantilly, Musée Condé, Ms lat 1047, f.37)

$\mathrm{T}$ The late 14th-century French repertory contains music characterized by an ingenuity and great subtlety whose terms of reference are entirely derived from within the art itself. One of the best-known French chansons of the period, the rondeau Fumeux fume by Solage, contains a superabundance of artifice, a wide variety of clever and audacious musical techniques. But in contrast to the extravagances of notation and rhythmic language that are the familiar hallmarks of the ars subtilior in music, the most striking feature of Fumeux fume is the proliferation of accidentals, and the bizarre tonal behavior they indicate. In addition to F, C, G, D, A, E and B, the pitches notated include $\mathrm{B} b, \mathrm{E} b, \mathrm{~A} b, \mathrm{D} b$ and $\mathrm{G} b$, as well as $\mathrm{F}^{\#}, \mathrm{C}^{\#}$ and $\mathrm{G}^{\#} .{ }^{1}$ These accidentals are the cause of virtually all the editorial problems in Fumeux fume, and in order to assess clearly just what subtilitas there may be in its tonal language, this article presents (as Example 1) a new edition, together with a defense of its idiosyncracies. Of necessity, such an edition constitutes a version that irons out the source's ambiguities, and interprets its pitch notation as an indication of how this chanson was meant to go. It clearly accepts the presumption that most of the composer's intentions with respect to pitch can be recognized and restored from the existing source evidence; the problem is not so much the intractable one of musica ficta as the soluble one of musica recta.

Fumeux fume has appeared in two recent scholarly publications that present careful transcriptions from its unique source, the famous Chantilly codex. ${ }^{2}$ Neither of these can be recommended to performers, as neither fully addresses the interpretation of the source accidentals; in some ways both are an edition of the source but not an edition of the piece. Though the need for a strong editorial hand is clearer in the case of Fumeux 
fume than in many other examples that could have been chosen, the principle demonstrated is a general one. An editor needs actively to use his intelligence and musical insight in order to make informed choices where intervention is necessary; he must make them in the light of as much knowledge and experience of the sources, the music, and contemporary theory as can be assembled. There is no avoiding the fact that choices have to be made even when, as here, only one source is concerned. ${ }^{3}$
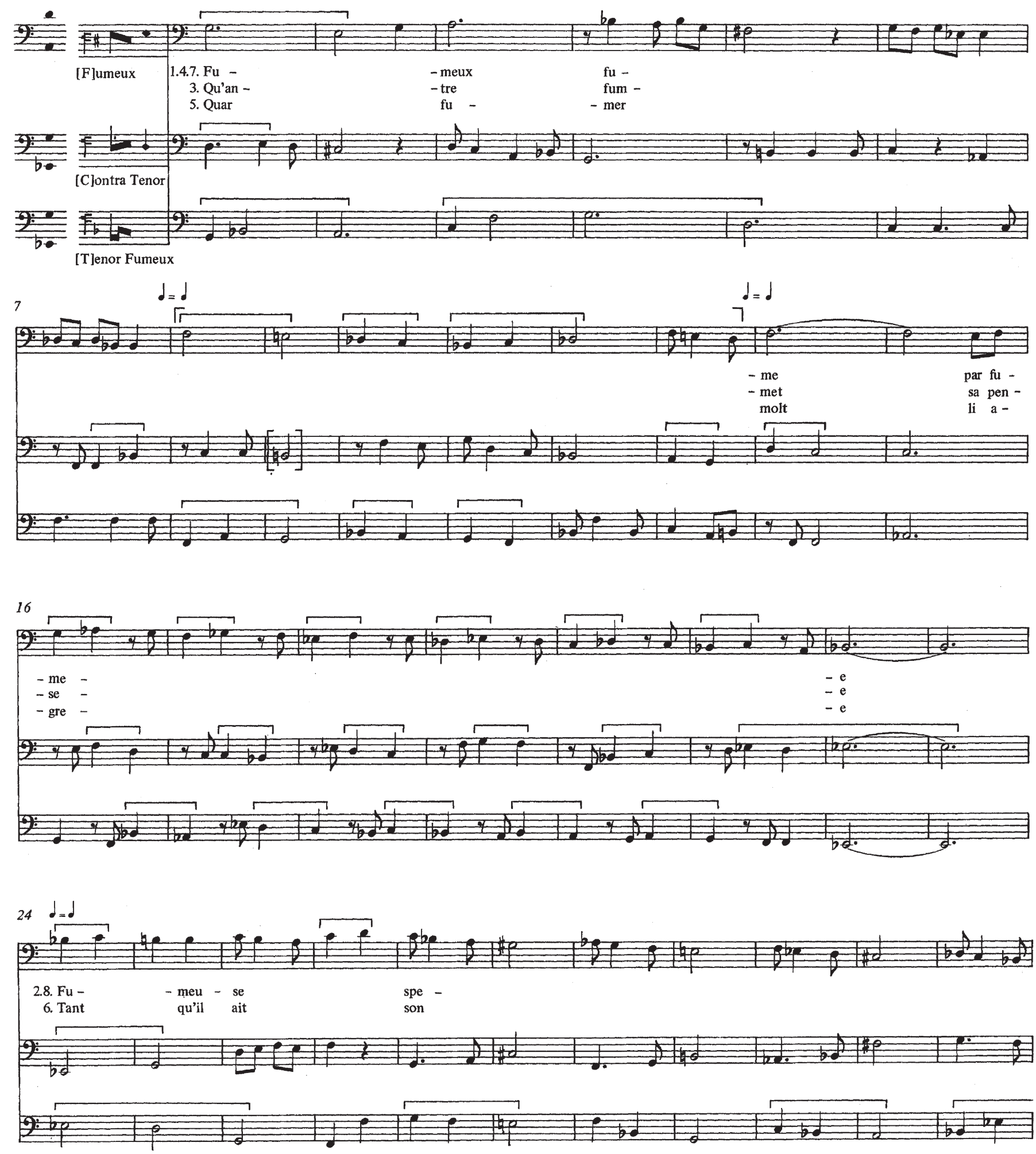

Example 1. Solage, Fumeux fume. 


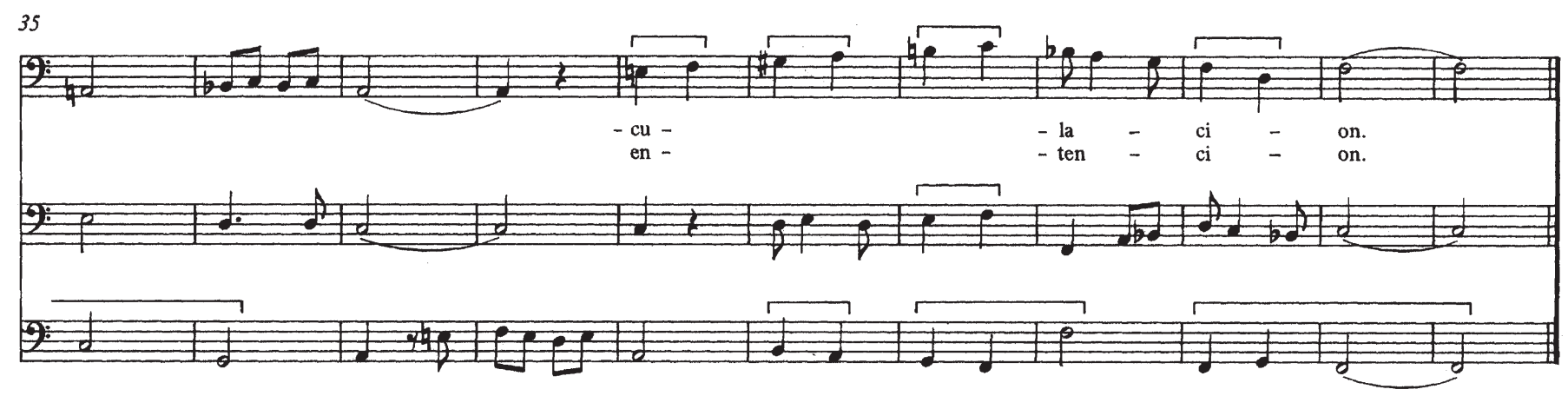

Example 1. Solage, Fumeux fume (cont.).

Indeed, a 'mere' transcription or diplomatic facsimile must resolve some ambiguities, even though this would not be its prime intention. But a scholarly edition in modern notation that is intended to be a kind of 'Urtext' simply giving a clean reading of the source is not acceptable in later 14th-century polyphony. As a concept 'Urtext' is unthinkable for such a piece as this chanson, even if it is imagined that the performer is experienced in modifying the printed text in order to produce a performable piece.

Fumeux fume illustrates the difficulties both in establishing a transcription and in going on to produce an edition. Even the initial act of transcription is no mere mechanical task, but one in which the editor must face up to the resolution of a host of problems, for the Chantilly manuscript is notorious for its scribal inconsistency with respect to the position of accidentals on the staff. Editorial decisions immediately have to be made: is this an $\mathrm{A} b$ or a $\mathrm{B} b$, an Ebor a $\mathrm{D} b$ ? Some interaction is immediately set off between the process of transcribing and the end product envisaged, in which choices are colored by anticipation; in order to make these choices, the editor must hold some notion, however flexible, of what he imagines the end product to be like, or in other words, what the composer intended. Temporarily settling these choices, he arrives at an intermediate point (somewhat like the published editions of Apel and Greene) where some decisions have been made, but the editorial task cannot be considered completed. Next, in respect of those accidentals, he must operate ficta like the medieval singer, presuming that from the point at which an accidental is entered into the staff, the hexachordal system that it implies remains in force until over-ridden by a subsequent accidental. ${ }^{4}$ In this instance, to follow through the full hexachordal implications of these accidentals would have been a rigorous exercise for the singer, and it is certainly a major task to be faced by the modern editor. In this respect he must transcend the vi- sual image both of the source and of his transcription, and be constantly alert to the results, both melodic and harmonic, of this process.

Problems arise at several crucial points in Fumeux fume, where choices must be made that are not simply axiomatic, usually because of awkward melodic or harmonic intervals, but also because of the lack of consistency in the execution of some tonal design. The editor may be compelled to revise a decision about the intended position of an ambiguous accidental, perhaps to refuse to accept a source accidental altogether, or to override its continued effect where not cancelled in the source, or indeed to add further accidentals. All the manuscript accidentals given for Fumeux fume in the Chantilly manuscript are listed in the Appendix to this article; for the edition some have been accepted and some amended without remark, but comments have been supplied for the more significant points where a choice of pitch is involved.

The version of Fumeux fume to emerge from this editorial process is not so very different from the familiar one, and it is still perhaps not entirely well-determined, or as the composer imagined it in every detail. Yet the reading is reliable and secure enough to form the basis for an examination of the tonal behavior of the work, which demonstrates an economy of materials, a diversity in their handling, and a consistency of harmonic idiom and of broader gestures that together define its unique features and special position within the chanson repertoire.

The most striking and memorable moments of the chanson are the rhythmically vigorous, descending melodic and harmonic sequences found in each half, and in particular the triple-time passage from bars 16 to 21 and the duple one from bars 28 to 35 . The former presents the same rhythmic motif six times in each voice; the contratenor, true to its role as harmonic filler, is varied melodically, while the tenor matches the melodic rigor 
of the cantus after a bar and a half. At no point, even in the structural cantus and tenor parts, is the sequence of tones and semitones repeated exactly. In fact, it consists of an elaboration of the diatonic descending scale G-F-E-D $b-C-B b$, strictly harmonized in minor 3rds. This is shown most clearly by Example 2a, which presents a reduction of the music to the bare bones of the cantustenor framework, written in breves.

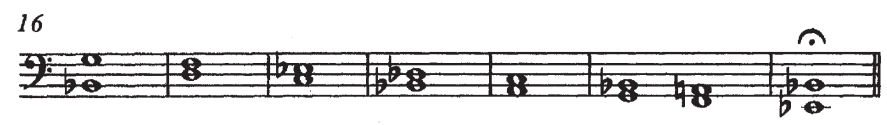

Example 2a. Fumeux fume, reduction of sequence, bars 16-22.

The sequence in bars 28-35 is of another kind, with two statements of a four-bar phrase, the second a 5th lower than the first. The phrase is exactly transposed in cantus and tenor (save for the necessary octave displacement of the tenor in bars 34-35), while the contratenor is again rhythmically but not melodically strict. Each phrase consists of two two-bar units in the cantus, of similar but not identical tonal content, spanning a diminished 4th (tone-semitone-semitone and semitonetone-semitone), with different tenor harmonizations. In each case the two-bar unit articulates a cadential pattern that is then side-stepped (major 3rd expanding to a 5th, and major 6th expanding to an octave). A reduction of this sequence is shown in Example $2 b$.

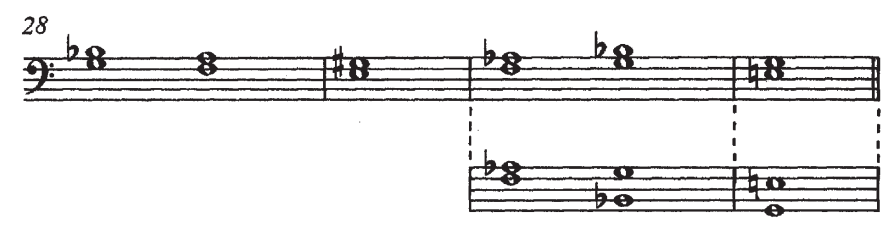

32

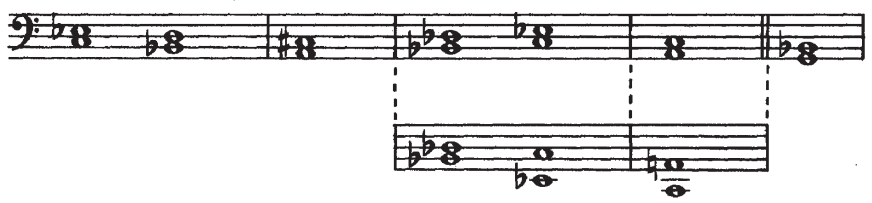

Example 2b. Fumeux fume, reduction of sequence, bars 28-35.

The only comparable passage in the later-14th-century chanson repertoire is the sequence that occurs in the secunda pars of the anonymous ballade Le mont Aon (shown for comparison, in reduction, as Example 3). ${ }^{5}$ This is in triple time, and similar to the first sequence here in its rhythmic motifs, and to both in its underlying chain of descending minor 3rds (major 6ths) and extreme accidentals.

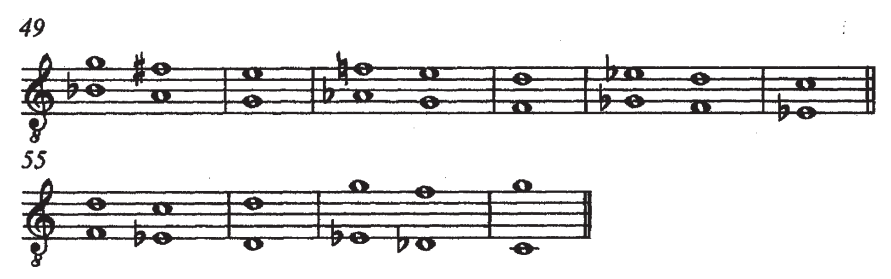

Example 3. Le mont Aon, reduction of sequence, bars 49-58.

In bars 29-30 and 33-34 of the second sequence, the singer is confronted with a sharp disjunction between the hexachords in which the same sounding pitch must be sung, changing from $m i$ to $f a$ between G\# and $\mathrm{Ab}$ and $\mathrm{C \#}$ and Db. This is the most dramatic consequence of the tonal content and rigor of the sequence, in which the cantus negotiates a similarly sharp disjunction from a flat to a sharp hexachord within each two-bar unit, as well as being confronted with the E-Eb cross relation of bars 31-32. Meanwhile the contratenor has to sing augmented 4ths and an augmented 5th. Nothing quite so disorientating happens to the singers in the sequence of bars 16-21, although the Eb specified in the cantus in bar 18 moves abruptly away from the tonality of the (also specified) Gb of the preceding bar (and removes any notion of an Eb-Fb semitone). The present reading leaves two diminished 5ths sounding between cantus and tenor (bars 19 and 20) as well as one between cantus and contratenor (bar 17); all occur in metrically weak positions, however.

The essence of the descending scalar material of the second sequence (bars 28-35) is the same as that of the first (bars 16-21); hence, it can be regarded as a transformed and rhythmically compressed variation of it. The common tonal material makes its first, and most condensed, appearance in the brief sequence of bars 6-7 and is then prolonged in bars 10-12 to delay the resolution of a cadence on $\mathrm{F}$ (begun in bars 8-9 but only reaching its goal in bar 14). This scalar material, with its harmonic 3rds, and its melodic goal $\mathrm{B} b$, is used as a contrast to the prevailing tonality with its final on F. In this regard, the fact that the medial cadence of the rondeau is on grave-register $\mathrm{B} b$ in the cantus (supported by the tenor on $E b$ ) is of the greatest significance. This cadence is unique in the entire chanson repertoire for its employment of the 5th below the cantus final as a secondary tonal goal. ${ }^{6}$ The novelty of this feature was surely its raison d'être for Solage, and the point would not have been lost on the contemporary singer, even if its significance escaped his listeners. 
The sequences, and the tonal area they introduce, are part of a larger-scale set of gestures that define the phrases or periods of this chanson. Each one can be regarded as the melodic prolongation of a note, followed by a release into sequence and cadence. Understood this way, they comprise firstly the melodic hovering around $G$ in the cantus in bars 1-6, followed by the sequence of bars 6-7; secondly, a hovering around $F$ in the cantus in bars $8-16$, followed by the sequence of bars 16-21 and cadence on $\mathrm{B} b$ in bar 22; thirdly, the hovering around $C$ in the cantus in bars 24-28, followed by the sequence of bars 28-35 with its chain of side-stepped cadences, the last of them toward $B b$; and finally the sustained grave-register A of bars 3539 (and A-C-E sonority) which discharges into the ascending sequence of bars 39-41 (semitones rising to $\mathrm{F}$, A, C) and the final cadence on F. ${ }^{7}$ Two striking parallels give further definition to these gestures. In the prima pars the precise contours of the cantus and tenor lines of bars 1-3 are recalled at bars 14-16, a tone lower, with only slight variation; in the secunda pars a parallel may be recognized between bars 24-32 and 39-45 in the appearance of ascending binary ligatures, and in the melodic emphasis on $\mathrm{C}$, especially as harmonized by $\mathrm{F}$ in the tenor a 12th below, followed by a drive downward towards a cadence on F.

The two major sequences also highlight another refinement, namely the consistency and unusual density of the harmonic language of Fumeux fume. This results from the exploitation of an unusually tight cantus-tenor framework relying much more on 3rds and 5ths than on 6ths and octaves. The contratenor fills in as best it can, more often making ${ }_{3}^{5}$ and ${ }_{3}^{6}$ sonorities than ${ }_{5}^{8}$ ones; sometimes it sounds above the cantus and tenor (as in bars 10-11, 19, 21-22, 33-36), and not infrequently has to resort to unisons or odd leaps. The texture is thus quite thick and saturated with imperfect consonances. Cantus and tenor often cadence to a 5th rather than an octave (as at bars 6, 23, 27, 41), and the avoidance of a major 6th-octave cadence, or its irregular resolution, is a frequent and characteristic event not just in the major sequence of the secunda pars but also elsewhere (as in bars 9-10, 13-14, 25-26, 43-44, and possibly intended in 2-3). Other unusual features worth noting include the exchange of register between cantus and tenor in bar 7, and the exchange of role between tenor and contratenor at bars 12-14.

As far as contemporary singers were concerned, however, the most striking of the unusual tonal features of Fumeux fume would surely have been the pitch level at which it is notated, a very rarely encountered, low register of the gamut with cantus final on grave $\mathrm{F}$ and tenor final an octave below on the F below Gam- ma-ut. ${ }^{8}$ But there is no compelling musical reason for this notation. The ranges of the three voice-parts are normal (just over an octave), as are their dispositions in respect to the final (the cantus is plagal while the tenor and contratenor are authentic), and their overall range (an octave and a 5th from $\mathrm{F}$ to $\mathrm{C}$ plus a tone above and below). Just as important, the part-writing is such that, aside from the proliferation of distant accidentals, the chanson would have been recognized as belonging to a familiar class of pieces sharing certain tonal characteristics: the third above the final is major, and there is frequent tonal fluctuation between the two forms of the 4 th above and the note below the cantus final. In Fumeux fume this fluctuation occurs between B and B b in the acute register and between $\mathrm{E}$ and $\mathrm{E} b$ in the grave register. Singers would have been familiar with pieces of similar tonal features notated either on $\mathrm{B} b$ when they had been doubly transposed flatwards, on F (normally an octave higher, of course) when singly transposed flatwards, on $C$ when untransposed, or on $G$ when transposed sharp-wards (though this was rare), and so on. ${ }^{9}$ In an all-vocal performance, they would have pitched all these at approximately the same level, that is to say, wherever they normally pitched chanson polyphony that spanned an overall range of just under two octaves.

The question why any particular piece of late Gothic music behaves as it does - what were the composer's intentions and how he set out to achieve them - is normally very difficult to answer. A large part of the importance of Fumeux fume lies in the fact that it is possible to suggest an answer, viewing Solage's musical subtilitas as a compositional response to the text's subtilitas. The composer sought a parallel in musical terms to the Affekt - the overall character - of his text, mirroring its brevity and density, its lack of immediately apparent comprehensibility, its appeal to an exclusive circle, the rhetorical skill of its word play and the obscurity of its allusion.

The text is clearly associated with the society of fumeurs of whom Deschamps speaks, and that prompted another work in the Chantilly manuscript, Hasprois' ballade Puis que je suis fumeux. ${ }^{10}$ Although text and music share the "insiders only" ideology, the relationship between them, beyond the association of Affekt, is relatively abstract. In the main, the rondeau responds only to the bipartite form of the two-line rondeau refrain; on a more specific level it is essentially melismatic in concept, a play with tones. ${ }^{11}$

To borrow from the language of the text, the intention of Fumeux fume was to speculate on certain tonal and notational possibilities. It must have challenged the singer to apply his craft rigorously, with intriguing 
and unaccustomed results - not forbidden or impossible, but transgressing familiar norms. He was required to sing strange melodic and harmonic intervals, to negotiate distant hexachordal systems and manage abrupt disjunctions, rather than smooth conjunctions, between them, to land at a very odd place at the medial cadence; furthermore, all this had to be confronted in notation that worked, but was situated in a very unfamiliar place on the gamut.

But surely the chanson was meant for listening as well, and to the ear there was (and is) subtilitas in the insistent, rigid descending sequences and repeated rhythmic figures, the waywardness and tonal color, the motivic consistency of harmonic and melodic 3rds and semitones. Though the experiences of reader, singer and listener would all have been different, they would have found, as we do, ingeniousness, craft, and musical integrity in the matching of a curious affect-witty brilliance and murky opacity - in the mediums of language and music.

Peter Lefferts is an assistant professor in the Department of Music at the University of Chicago. His scholarly work has mostly concentrated on English polyphony of the 13th and 14th centuries.

\section{Notes}

1. The range of accidentals immediately raises speculation about the tuning system for which this chanson was conceived. The notes comprise 15 of the 16 of a Pythagorean tuning in which $F \#=G b, C \#=D b$, and $G \#=A b$. Left undetermined, because of the note not specified (either D\# $(=\mathrm{E})$ or $\mathrm{Cb}(=\mathrm{B})$ ) is the position of the bad 5th (harmonic wolf). This would either have been between $\mathrm{B}$ and $\mathrm{F} \#=\mathrm{Gb}$ (with D\#) or between $E$ and $B$ (with $B=C b$ ). Neither of these bad 5ths is written between cantus and tenor, but the B-E 4 th occurs between cantus and contratenor in bars 9 and 31, and the B-F\# 5 th occurs between cantus and contratenor in bar 5 .

2. In its unique source, $\mathrm{F}-\mathrm{CH} 564$ (the Chantilly codex), f.59r, Fumeux fume is legible and complete, with just one missing breve in the contratenor that is easily supplied (bar 9) and one pitch problem in a tenor ligature that is not difficult to sort out (bars 34-36; see Appendix). Two additional amendments suggested in the Appendix but not carried out in the present edition involve cantus, bar 2, and tenor, bar 21. The chanson is published in W. Apel, ed., French Secular Compositions of the Fourteenth Century, Corpus Mensurabilis Musicae [CMM],liii (Rome, 1970-72), i. no. 103, and G. Greene, ed., French Secular Music, Polyphonic Music of the Fourteenth Century [PMFC], xix (Paris and Monaco, 1982), no. 98.

3. For two eloquent arguments in favor of a strong editorial hand, see M. Bent, "Some criteria for establishing relationships between sources of late-medieval polyphony" in Music in medieval and early modem Europe, ed. I. Fenlon (Cambridge,
1981), pp. 295-317, and R. Taruskin, review of J. Caldwell, Editing early music, in MLA Notes xlii/3-4 (1986), pp. 77579 . On the problems of editing the late 14th-century repertoire in particular, see L. Koehler, review of G. Greene, ed., French Secular Music, PMFC, xviii-xix, in JAMS, xxxix (1986), pp. 633-41.

4. The understanding of the meaning of the accidentals that I am assuming here is that worked out over two decades ago by Andrew Hughes and Margaret Bent in their work on the Old Hall manuscript, and published in A. Hughes, Manuscript accidentals: Ficta in focus 1350-1450, Musicological Studies and Documents, xxvii (AIM, 1972), and M. Bent, "Musica recta and musica ficta," Musica disciplina, xxvi (1972), pp. 73-100.

5. Le mont Aon is found in two sources, F-CH 564 (Chantilly), f. 22v, and I-Fn 26 (Panciatichi), f. 103v-104. It has been edited by Apel, op. cit., CMM, liii, ii, no. 159; by Greene, op. cit., PMFC, xvii, no. 22; and by the present author in Five Ballades for the Counts of Foix, to be published by Antico Edition.

6. By secondary cadential goal I mean specifically the ouvert of the ouvert-clos pair in a ballade or virelai, the pre-refrain cadence in a ballade, and the medial cadence in a rondeau. A rondeau with an $\mathrm{F}$ final in this context would usually cadence either on A, a 3rd above the cantus final, or on E, a semitone below it.

7. These gestures are underlined rhythmically by the frequency of attack on the pulse level, and clarified mensurally as well, by the change of mensuration in bars $8-13$, for instance, and by the prevailingly binary modus, into which all periods or phrases fit squarely after the first three bars.

8. In the later 14th- and early 15th-century repertoire of vernacular song, the low F final, with plagal cantus melody and octave cadences, is known in only three examples. Apart from Fumeux fume, they are Matteo da Perugia's ballata Gia da rete d'amor and Thomas Fabri's rondeau Die mey so lieflic wol ghebloit (see R. Strohm, Music in Late Medieval Bruges (Oxford, 1985), pp. 206-7). Only two lower-pitched settings are known, one that uses grave-register $C$ as the final of a plagal cantus melody, the ballata Deduto sey, an opus dubium of Ciconia (see M. Bent and A. Hallmark, The Works of Johannes Ciconia, PMFC, xxiv (Paris and Monaco, 1985), no. 42) and one similarly using grave-register D, Matteo da Perugia's virelai Helas que feray (Apel, op. cit., CMM, liii, i, no. 58). All these can be viewed as transpositions downward in the gamut of polyphony that could just as well have been, and normally was, notated an octave higher. On the other hand, there is another way in which very low finals were conceived and employed, at the bottom of the available space for the cantus voice. Here they were reserved for the notation of authentic melodies, with the final cadences of polyphonic settings ending with cantus and tenor in unison. In Machaut's chansons, for instance, the final on $\mathrm{F}$ is found only in the grave register (never the acute) and only associated with authentic melodies and unison final cadences. It is used for just one of 42 polyphonic ballades (no. 12), and no rondeaux, but in 11 of 33 virelais, 4 polyphonic (nos. 24, 29, 30, 32) and 7 monophonic (nos. 2, 6, 8, 12, 15, 22, 33). In the later French repertoire, grave-register $\mathrm{G}$ apparently stands at the bound- 
ary between these ways of handling the low final and can adopt either role. In Apel's French Secular Compositions, six chansons with grave-register $\mathrm{G}$ final have an authentic cantus (ballades nos. 29, 53, 114, 137, 149, 159; virelai no. 14, and rondeau no. 248), while eight further chansons have a plagal cantus (ballades nos. 23, 108, 111, 119; rondeaux nos. 67, 238, $249,284)$.

9. A full exposition of the characteristics of this class of tonal types may be found in my forthcoming study, "Tonal systems and tonal types in the late fourteenth-century French chanson."

10. Fumers are members of a clique ("l'ordre des Fumeux"), a "confrérie imaginaire" (Raynaud) or "confrérie burlesque" (Poirion), which if grounded in reality may have been an informal literary drinking and debating society. This organization was the brainchild of the young Eustache Deschamps (1346-1406), who wrote out a poetic charter of 254 lines for it (Le chartre des Fumeux, dated 9 December 1368) that begins "Jehan Fumée, par la grace du monde/ Ou tous baras et tricherie habonde/Empereres et sires des Fumeux,/ Et palatins des Merencolieux." There are three other relevant poetic "chartres et commissions" of Deschamps, beginning "Eustace, empereur des Fumeux," "Comme debas et questions/ et fumeuses dissenciona/Fussent hier meuz en la taverne,/ Ou nostre empire se gouvernet," and "L'empereur de toute Fumée/qui a mainte chose fumée"; the last is dated 4 November 1370. See Oeuvres completes de Eustache Deschamps, vol. vii, ed. Gaston Raynaud (Paris, 1891), pp. 312-342, and Daniel Poirion, Le pote et le prince, L 'évolution du lyrisme courtois de Guillaume de Machaut Charles d 'Orleans (Paris, 1965), p. 223. The Hasprois ballade has been edited by Apel, op. cit., CMM, i, no. 42 and by Greene, op. cit., PMFC, xviii, no. 47.

It is next to impossible to fully capture the dual sense of "fume" in English with a single image. Firstly there is the deep-seated association of smoke and wrath, so the text may speak of irascible, discontented grumbling and letting off steam. Secondly there is the sense of a merely whimsical and capricious woolgathering on account of the hazy, nebulous, insubstantial nature of steamy vapors. A kind of mediating set of associations follows from the fact that "fumeux" can mean drunk, intoxicated on noxious alcoholic vapors rising from the stomach to the head and clouding reason, leading to vain contentiousness and idle boasting - a lot of "hot air."

To the available translations of Fumeux fume I should like to add the following, the work of Dr. Sylvia Huot of the Department of Foreign Languages and Literatures of Northern Illinois University, who not only shared her thoughts on the rondeau text (on which I draw above) but also kindly agreed to provide one translation - and came up with three:

Smoky smolders smokily/In smoky speculation./ Thus he steeps his thoughts in smoke./Smoky smolders smokily./For it suits him well to smoke/ Until he gets his way./Smoky smolders smokily/In smoky speculation.

Grumpy grumbles grumpily/In grumpy speculation./His thoughts are fogged by grumpiness./ Grumpy grumbles grumpily./For it suits him well to gripe/Until he gets his way./Grumpy grumbles grumpily/In grumpy speculation.
The grouch fumes wrathfully/In wrathful speculation./His thoughts are fogged by wrath./The grouch fumes wrathfully./For its suits him well to fume/Until he gets his way./The grouch fumes wrathfully/In wrathful speculation. “

11. Apel and Greene carefully follow the word underlay of Chantilly. The present edition ventures a slightly different solution in order to open up the question of whether the scribe accurately represented the composer's intention, or indeed, whether the composer had a fixed intention with regard to the distribution of syllables. It is my opinion that the source is not to be followed slavishly and that modern editors (and performers) should feel free to amend text underlay within the bounds of understood stylistic norms (such as the observation of the caesura and the preservation of the contrast between relatively syllabic delivery and lengthy melismas) to suit their concept of the melodic logic and gesture of the particular chanson.

\section{Appendix: \\ Manuscript accidentals and choice-of-pitch cruxes}

Cantus accidentals

bar 1 \# on $\mathrm{F}$ before $\mathrm{G}$

bar $4 b$ on $B$ before first $B$

bar 6 b on $\mathrm{E}$ (almost D) before first $\mathrm{G}$

bar $7 b$ on $C$ before first $\mathrm{D}$

bar 8 \# on $\mathrm{D}$ (almost $\mathrm{E}$ ) before $\mathrm{F}$

bar $10 b$ on $\mathrm{D}$ before $\mathrm{D}$

bar 13 \# on $\mathrm{E}$ before $\mathrm{F}$

bar 16 b on A before $G$

bar $17 b$ on $\mathrm{F}$ before $\mathrm{F}$

bar 18 b on E before $\mathrm{E}$

bar $19 b$ on $\mathrm{D}$ before $\mathrm{D}$

bar $21 b$ on $B$ before $B$

bar $24 b$ on B before B

bar 25 \# on B before B

bar 29 \# on $\mathrm{G}$ before $\mathrm{G}$

bar 30 b on A before A

bar 31 \# on $\mathrm{F}$ before $\mathrm{E}$

bar 32 b on $F$ (almost $G$ ) before $F$

bar 33 \# on D (almost E) before C

bar 34 b on $\mathrm{D}$ before $\mathrm{D}$

bar 35 \# on B (almost A) before A

bar 36 on $B$ before first $B$

bar 39 \# on $\mathrm{E}$ before $\mathrm{E}$

bar 40 \# on $\mathrm{G}$ before $\mathrm{G}$

bar 41 \# on $B$ before $B$

bar $42 b$ on A before B

Cruxes

bar $2 \mathrm{E}$ or $\mathrm{F} \#$ / choose $\mathrm{E}$

This is the conservative choice: initial accidental (sharp on F) suggests opening two-breve ligature to have been intended as G-F\#, setting up a side-stepped cadence on $\mathrm{G}$ in bars 2-3 and establishing melodic motion of bars 1-6 in cantus even more strongly as prolongation of neighbor-note motion round $\mathrm{G}$. 
bar $5 \mathrm{~F}$ or $\mathrm{F \# /choose} \mathrm{F \#}$

Creates cadential motion to G-C 5th via major 3rd: signed B natural in contratenor suggests doubled leading tone sonority; anticipates diminished 4 th motif (descending minor 3rd plus semitone) of sequence in 29-35; see also comments on possible $\mathrm{F} \#$ in bar 2.

bar $12 \mathrm{D}$ or $\mathrm{D} b /$ choose $\mathrm{D} b$

Continuation of accidental in 10.

bar $28 \mathrm{~B}$ or $\mathrm{B} b /$ choose $\mathrm{B} b$

Preserves exact sequence by comparison with 32 .

bar $40 \mathrm{G}$ or G\#/ choose G\#

Clearly specified by accidental; preserves melodic and notational sequence; requires $B \curvearrowleft$ in tenor.

\section{Tenor accidentals}

bar $1 b$ on B (almost A) before $G$

bar $8 b$ on $B$ before $F$

bar 13 b on A before A

bar $15 b$ on A (almost G) before A

bar $17 b$ on $\mathrm{E}$ (almost $\mathrm{F}$ ) before $\mathrm{E}$

bar $17 b$ on $E$ before $D$ (after change of line)

bar $18 b$ on B (almost A) before B

bar $24 b$ on $E$ before $E$ (different hand)

bar 28 \# on $\mathrm{E}$ before $\mathrm{G}$

bar 30 b on B before B (unlike 1, 18)

bar 37 \# on E before $\mathrm{E}$

bar 41 \# on $\mathrm{G}$ before $\mathrm{G}$

\section{Cruxes}

bar $12 \mathrm{~B}$ or $\mathrm{B} b /$ choose $\mathrm{B}$

Continuation of source $b$ in 10 , and $B b$ to $F$ perfect 5 th more plausible than diminished 5th; anomalous tenor behavior in 12-13 more characteristic of a contratenor; the unison of tenor and contra on B in 12 is an awkwardness suggesting the successive addition of the contra and the subsequent amendment of the tenor as a result.

bar $13 \mathrm{~B}$ or $\mathrm{B} b /$ choose $\mathrm{B}$

Follows the most plausible intention of the accidental before the A (as signed $B \sharp$ ), canceling the source $b$ in 10; continues contra-like behavior of tenor, moving toward $\mathrm{C}$ in a cadence on F; appropriately perverse in its creation of a downward leap of an augmented 4 th tempered only slightly by the minim rest that intervenes.

bar $18 \mathrm{~A} b$ or $\mathrm{B} b /$ choose $\mathrm{B} b$

Reading with $\mathrm{A} \downarrow$ preserves cantus-tenor descent in parallel minor 3rds, at the cost of metrically weak diminished 5 th in 19 (but see bars 17 and 20).

bar 21 Amend first F to Eb?

Preserves the sequence better and avoids minor 7th with the contratenor.

bar $22 \mathrm{E}$ or $\mathrm{Eb} /$ choose Eb

bars 34-36 MS reads B b-D-B b-G/choose B b-Eb-C-G

Something clearly wrong with this four-note ligature; the amendment preserves exact sequence with 30-31, save for transposition down a 5th or up a 4th; Apel's and Greene's editions just amend the second $\mathrm{B} b$ to $\mathrm{C}$.

bar $41 \mathrm{G}$ or G\#/ choose G
Contratenor accidentals

bar 2 \# on D before $\mathrm{C}$

bar 5 \# on $B$ before first $B$

bar 6 b on A before A (similar to tenor 1, 18)

bar 12 \# on B before B

bar $17 b$ on $\mathrm{F}$ before second $\mathrm{C}$

bar $18 b$ on $\mathrm{F}$ before $\mathrm{E}$

bar 24 on $\mathrm{G}$ before $\mathrm{E}$

bar 29 \# on $C$ before $C$

bar 31 \# on $B$ before $B$

bar 32 b on B (almost A) before A

bar 33 \# on $\mathrm{F}$ (a little high) before $\mathrm{F}$

bar 42 b on $F$ (a little high) before $F$

\section{Cruxes}

bar $1 \mathrm{E}$ or $\mathrm{Eb} /$ choose $\mathrm{E}$

bar $3 \mathrm{~B}$ or $\mathrm{B} b /$ choose $\mathrm{B}$

General prevalence of $\mathrm{B} b$ in grave register; specific appearance in tenor, 1 ; signed $B \sharp$ in 5 , presumed to be canceling something; anticipates A-B $b-\mathrm{G}$ motif in cantus, 4; $\mathrm{B}$ Ł would normally resolve up by step to $\mathrm{C}$ in this register.

bar $12 \mathrm{~B}$ or $\mathrm{B} b /$ choose $\mathrm{B} b$

Contradicts source accidental, but tenor $\mathrm{B} b$ strongly indicated by continuation of $b$ in 10 and plausibility of B b-F leap of perfect 5th; maintains prevalence of $\mathrm{B} b-\mathrm{D} b-\mathrm{F}$ sonority over 6-12; sharp probably added for "descending semitone after syncopation" motif.

bar 42 Abor Bb/choose Bb

Slightly high $b$ before $\mathrm{F}$ in 42 taken as in tenor, bar 8 , as indicating once-transposed hexachordal system with grave-register $B$.

bar $43 \mathrm{~B}$ or $\mathrm{B} b /$ choose $\mathrm{B} b$

Follows from assumption of $\mathrm{B} b$ in 42 ; might amend to $\mathrm{B} \natural$ in this cadential context. 